\title{
PERSPECTIVAS AMERÍNDIAS NA ESTÉTICA CONTEMPORÂNEA
}

\section{Ana Carolina Cernicchiaro*}

\begin{abstract}
Resumo: A proposta deste trabalho é refletir sobre experiências interculturais que se abrem para as imagens, as narrativas, a poética, a estética e a ontologia ameríndias, como as oficinas para cineastas indígenas do Video nas Aldeias, a restauração do mito tupinambá em Meu destino é ser onça, de Alberto Mussa, a tradução dos cantos Caxinauás em Ouolof, de Herberto Helder, ou ainda a descentralização do cânone literário brasileiro na antologia Poesia.br, organizada por Sergio Cohn. Projetos que emprestam sua técnica (literária, cinematográfica, tradutória, editorial) para que esse outro fale de si e de nós enquanto outros. Neste contato, a literatura e o cinema brasileiro contemporâneos são afetados por um devir-minoritário que cava uma língua-menor na língua maior e desestabiliza a cultura padrão.
\end{abstract}

Palavras-chave: Literatura. Cinema. Ontologia amerindia.

Em seu famoso $O$ animal que logo sou, Jacques Derrida descobre (sob a perspectiva de um felino) que é ao outro que se deve fazer a pergunta sobre quem é este que eu sou: "Quem sou eu então? A quem perguntar, senão ao outro?" (DERRIDA, 2002, p. 18). É essa pergunta, tantas vezes repetida na história das artes, que agora parece receber seu destinatário adequado quando a literatura e o cinema contemporâneos deixam de falar sobre o outro e se colocam sob o olhar desse outro, quando emprestam sua técnica (literária, cinematográfica, tradutória, editorial) para que esse outro fale de si e de nós enquanto outros.

Considerando que, como diz Maurice Blanchot (2005), o sujeito implicado no fazer artístico caminha ao ilegível de sua própria existência, como um "personagem que assume o destino da impessoalidade", podemos pensar este abandono de si, este fim da autoridade do eu, como uma abertura em direção a outros pontos de vista, a outros devires. Pois somente onde a identidade está ciente de sua construção a partir do outro, somente onde o sujeito se assume como processo de identificação sujeito à diferença, é que o outro emerge.

Esta abertura da arte constitui uma ética da heterogeneidade que deixa irromper o olhar do outro e transforma a imagem em uma poética de alteridade. A ética que se revela neste processo se apresenta como práxis de afetação, de contato, de contágio. Trata-se de uma ética da alteridade e da heterogeneidade que transforma a arte em irrupção do olhar do outro. Isso porque a questão da ética pressupõe um reconhecimento do outro anterior à dicotomia eu-outro, mesmidade-alteridade. Neste sentido, ela é inseparável da política, porquanto a questão do político é a que nos vem do outro, a que é significada a partir do lugar do outro. Mas também da estética, já que este olhar do outro transforma a própria linguagem da arte, realiza um devir-minoritário da língua pela arte, revela uma presença irrepresentável, que coloca em jogo e desnaturaliza as formas fixas, homogêneas e excludentes da cultura dominante.

\footnotetext{
* Doutora em Literatura pela Universidade Federal de Santa Catarina - UFSC. Professora na Universidade do Sul de Santa Catarina.E-mail:anacer77@yahoo.com.br.
} 
Enquanto a institucionalização da cultura busca, através das exclusões e marginalizações, permanecer como coisa coesa, total, una; a arte assume a pluralidade em toda sua força, de forma que seus elementos permanecem pulsantes em sua singularidade. O outro não pode ser domesticado ou apropriado, interpretado ou familiarizado, pois apresenta sua resistência e irredutibilidade, dramatizando os modos familiares de entendimento. Desta maneira, a abertura para o olhar do outro implica introduzir na cultura matriz um germe, um corpo estranho que a desestabiliza (ATTRIDGE, 2004). O outro implícito na linguagem, que está sempre excluído para que ela continue sendo o que é (instrumento de classificação, inclusão e exclusão (FOUCAULT, 2006), se torna explícito nas invenções estéticas da arte.

Neste sentido, nos mostra Derek Attridge, o trabalho de inovação formal que mais estranha o leitor faz a mais desafiante demanda ética: "understand how little you understand me, translate my untranslatability, learn me by heart and thus learn the otherness that inhabits the heart" (2004, p. 130). Trata-se de um chamado para remodelar o que pensamos e o que somos, de forma a aprendermos a alteridade e a singularidade do outro. Trata-se, portanto, de um ato de hospitalidade e generosidade, pois, como diz Derrida (2003), um ato de hospitalidade é sempre um ato poético. Mas também político, afinal, não existe arte, avisa Jacques Rancière em Malaise dans l'esthétique, sem uma partilha do sensível que a liga a uma certa política: "A estética é esta partilha" (2004, p. 63). Da mesma maneira, a política também sempre é estética, pois é um modo de determinação do sensível, uma divisão dos espaços, uma forma de visibilidade e de dizibilidade do que é próprio e do que é comum (RANCIÈRE, 1995, p. $8)$.

É essa reconfiguração da partilha do sensível a partir da própria língua que vemos, por exemplo, em Ouolof, de Herbeto Helder. Nestes "poemas mudados para o português", Helder traduz os mitos ameríndios mantendo sua sintaxe original, uma sintaxe em devir, antropofágica, perspectivista. Como explica o próprio Helder, há uma preocupação em fazer da fala dos ameríndios a sua própria fala: "Essa fala, queremos fazê-la nossa. Temos diante de nós uma poderosa dicção mítica, mágica, lírica, transgredindo em todas as frentes a norma da palavra portuguesa. Este transtorno faz-se ele mesmo e imediatamente substância e acção poéticas" (HELDER, 1997, p. 44-45). O resultado é um texto gaguejante, onde uma língua estrangeira é escavada na língua e toda a linguagem sofre uma reviravolta. Essa gagueira, segundo a definição de Gilles Deleuze, é "uma sintaxe em devir, uma criação de sintaxe que faz nascer a língua estrangeira na língua, uma gramática do desequilíbrio" (DELEUZE, 1997, p. 127). Trata-se de um devir-minoritário da linguagem, uma forma de cavar uma língua menor na língua maior, dominante, padrão. Para entendermos melhor o que isso quer dizer, tomo a liberdade de citar as duas primeiras estrofes do longo poema, que trata do mito de criação da lua entre os índios Caxinauá da Amazônia:

\footnotetext{
Do caxinauá seu nome seu feiticeiro é.

Caxinauás muitos pelejarem para suas gentes ajuntaram, aqueles com pelejam.

Da vespa as gentes, muito corajosas muito,
} 
ali do sol do rio à beira,

da vespa as gentes moram. Caxinauás de capivara rio

com moram, os

caxinauás do sol do rio ciosos

são.

Os binanauás noite dentro dormem todos, deitados

estavam, os caxinauás

escuro dentro cacete com espancaram-nos,

acabaram. Um só, sono com

acordou, o terçado tirou, de feiticeiro nauá,

lobonauá,

a cabeça degolou. Seu corpo caiu, está deitado,

a cabeça rolando, rolando vem

por todo o caminho.

Muitos de corpos inteiros vêm, lobonauá ele só,

decapitaram,

sua cabeça só rolando vem por todo o caminho.

Suas gentes ele com penalizadas chorando vem por todo o caminho

(HELDER, 1997, p. 48).

No resto do poema, a cabeça continua rolando e se transformando incessantemente, em alimentos, peixes, caças, sol, noite, lua..., numa variação constante, num devir infinito, que desterritorializa toda identidade, inclusive a da língua portuguesa, a língua-mãe, esse órgão que, como nos lembram Deleuze e Félix Guattari, é um instrumento de exclusão e de dominação. O poema se apresenta, assim, como um devir-minoritário da linguagem, como uma forma de cavar uma língua menor na língua maior, dominante, padrão, que impõe regras sintáticas, lexicais, gramaticais, mas também morais, nacionais, identitárias, etnocêntricas. Conforme avalia Silviano Santiago, evitar o bilinguismo significa impor o poder colonialista. Segundo ele, "na álgebra do conquistador, a unidade é a única medida que conta": uma só Língua, a verdadeira Língua, como um só Rei, o verdadeiro Rei (SANTIAGO, 1978, p. 16).

Segundo Deleuze e Guattari, a língua maior é a língua da maioria, no sentido político e não quantitativo do termo, ou seja, a língua do "homem-branco-masculinoadulto-habitante das cidades-falante de uma língua padrão-europeu-heterossexual" (DELEUZE; GUATTARI, 1995, p. 55). Fazer a língua materna devir-menor é, portanto, desestabilizar a língua do poder e da dominação, levando a linguagem a escapar de seu uso maior, "uso de Estado, língua oficial" (PELBART, 2000, p. 70). As línguas menores são agentes potenciais para fazer a língua maior entrar em um devir-minoritário, para colocá-la em variação contínua (DELEUZE; GUATTARI, 1995, p. 56).

Contra a altivez da língua-maior colonizadora, do discurso triunfal dos vencedores, estas línguas-menores ainda têm muito para falar, apesar de todos os projetos políticos, sociais, jurídicos e culturais de exclusão. É preciso escutar essas línguas como quem abre a história, uma abertura que, nos lembra Michel Löwy a partir das teses sobre o conceito de história de Benjamin, é "inseparável de uma opção ética, 
social e política pelas vítimas da opressão e por aqueles que a combatem" (LÖWY, 2005, p. 159).

Essa opção ética de liberar o murmúrio dos vencidos sob a história oficial e de rememorar a língua indígena esquecida, emudecida, calada sob o discurso nacional, é o que move a restauração do mito tupinambá feita por Alberto Mussa em Meu destino é ser onça. Nela, Mussa propõe pensar a cosmogonia tupinambá como "uma autêntica epopéia mítica", com a mesma grandeza de suas congêneres (MUSSA, 2009, p. 26).

O livro carrega a marca do vestígio e das pegadas deixadas pelos indígenas. Em seu trabalho de corte e montagem de citações, o autor ultrapassa as fontes originais para rememorar a voz desse outro que estava escondida já na fala dos primeiros viajantes. Desta maneira, paira sobre o texto um espectro de nossa história que está obliterado há cinco séculos, de forma que sua intervenção renova o conceito de história, como potencializadora das singularidades que habitam o país, como forma de reverter o método de esquecimento e exclusão constitutivo de nossa história oficial e de abrir o mundo (e a nós mesmos) para novas perspectivas.

Ao borrar os contornos entre ficção, teoria, mito, rito, pesquisa histórica, antropológica e etnográfica, Mussa desenvolve um texto do limiar, errante e em trânsito. Já no preâmbulo, chama a atenção para o caráter literário de seu ensaio ficcional, que busca a restauração de um original possível, e não o resgate de uma gênese absoluta. Desta forma, o autor revisita o arquivo, não para recuperar um exotismo, mas para disseminar as cinzas, para devolver potência à literatura como pensamento selvagem: "Senti, assim, um impulso incontrolável de incorporar a epopéia tupinambá à nossa cultura literária. Para tanto, era insuficiente traduzir a prosa confusa de Thevet e recompor a ordem interna dos episódios: faltava essencialmente devolver à narrativa sua literariedade" (MUSSA, 2009, p. 26).

Esta literariedade é a literariedade de um texto-onça, de uma espécie de des-obra, de um excesso significante que se lê nas margens da representação e que assinala, percebe Raúl Antelo, "un más alla de la representación, un más allá de la territorialidad, un más allá de la nación" (ANTELO, 2011, p. 132). O trabalho de Mussa revela uma experiência de toque entre corpos heterogêneos, afinal, nos lembra Antelo, longe de ser um animal totêmico de um grupo fechado, a onça, o jaguar é um poderoso índice de disseminação cultural (ANTELO, 2011, p. 136), presente numa extensa série de textos latino-americanos, uma série do indomesticável, do indomável. Tal indomável é o que, para Lévi-Strauss (1989), caracteriza o pensamento selvagem, não o pensamento dos selvagens nem o de uma humanidade primitiva e arcaica, mas um pensamento em estado selvagem, não domesticado ou cultivado, que não visa um rendimento, uma função. É justamente esse caráter indomesticável que transparece na arte que se deixa afetar pela estética ameríndia, expondo uma sobrevivência que é pura resistência. "No se trata sólo entonces de historicizar una escritura y, consecuentemente, espacializar el tiempo, es decir, desexistencializarlo, sino de temporalizar una enunciación, postular una diferencia de los lugares sociales y simbólicos, que en última instancia es una forma de proponer un existencialismo de izquierdas", afirma Antelo (2011, p. 146).

Semelhante embaralhamento dos lugares sociais e simbólicos vemos no processo de descentralização do cânone literário brasileiro da coleção Poesia.br, organizada por 
Sergio Cohn e publicada pela Azougue Editorial em 2012. Cohn desvia o marco inicial de nossa história literária ao iniciar sua antologia de dez volumes com um tomo intitulado Cantos Ameríndios, onde estão reunidos cantos de seis etnias indígenas (Araweté, Bororo, Kashinawá, Marubo, Mbya Guarani e Maxakali) na tradução de poetas brasileiros contemporâneos, como Antonio Risério, Sérgio Medeiros, Daniel Bueno, Pedro Cesarino, Josely Vianna Baptista, Douglas Diegues, Guillermo Sequera e Rosângela de Tugny.

A antologia não apenas estende o critério cultural e linguístico da nacionalidade (a qual Brasil nos referimos quando nos intitulamos brasileiros?), mas também coloca em questão o recorte cronológico de nossa história literária, que tradicionalmente começa com os colonizadores. São textos que evidenciam problemáticas pré e pós-coloniais, primitivas e pós-modernas, como a própria ideia de autoria e assinatura (afinal, quem assina cantos coletivos, performances transmitidas oralmente de geração em geração? ${ }^{1}$ ). Sem contar, é claro, as inovações estilísticas e rítmicas que afetam toda uma poética contemporânea. Cito Cohn:

\begin{abstract}
Os poemas aqui reunidos compartilham a dupla circunstância de serem contemporâneos e anteriores a todos os outros textos constantes na coleção Poesia.br. Por isso, este pode ser considerado o seu volume de abertura, mas também pode ser visto como sua conclusão.

Explico melhor. Anteriores por pertencerem a culturas que estavam presentes no território que hoje chamamos de Brasil antes mesmo da chegada dos primeiros colonizadores europeus. Se não possuímos registros escritos dos cantos destes povos naquela época, é possível pressupor que guardariam graus de familiaridade com os aqui publicados - embora as culturas de que fazem parte não sejam, de modo algum, estanques. E contemporâneos porque se os últimos cinco séculos foram marcados pelo terrível desaparecimento de diversas culturas que habitavam este continente, outras, inclusive as presentes neste volume, felizmente sobreviveram, estão presentes e potentes, criando e reproduzindo seus cantos na atualidade. E também porque esses poemas trazem em si questões que marcam algumas das mais agudas questões da poesia contemporânea: o esboroamento da autoria e das fronteiras das expressões artísticas, a presença da performance como parte significante, a quebra do texto enquanto monumento, entre outras (COHN, 2012, p. 7).
\end{abstract}

Outro sinal da contemporaneidade desses cantos é a forma como eles afetam a produção desses poetas; penso no livro Roça Barroca de Josely Vianna Baptista, no portunhol selvagem de Douglas Diegues ou na indecidibilidade entre natureza e cultura na poesia de Sérgio Medeiros, por exemplo. Vejamos um trecho da tradução de Medeiros para o canto Bororo de caçada das antas:

\footnotetext{
Anta, dona anta, que bela é tua coroa de penas!

Anta, dona anta, que belo é teu colar de plumas!

Anta, dona anta, que bela é tua pintura de barro claro!

Anta, dona anta, que belo é teu chocalho na canela!

(apud COHN, 2012, p. 20).
}

\footnotetext{
${ }^{3}$ Daí Barthes concluir que o xamã das sociedades primitivas é uma alternativa ao autor positivista, enquanto perda de origem da voz no texto: "nas sociedades etnográficas, a narrativa nunca é assumida por uma pessoa, mas por um mediador, xamã ou recitante, de quem, a rigor, se pode admirar a performance (isto é, o domínio do código narrativo), mas nunca o 'gênio"' (BARTHES, 2004, p. 58).
} 
Vejamos agora um trecho do poema "Flower Irlandês", do livro Totens do mesmo Medeiros, também publicado em 2012:

\author{
formigas carregam harpas verdes \\ cruzam com outras com tambores igualmente verdes \\ (MEDEIROS, 2012, p. 43).
}

Ou a letra I do poema "ABCdário do matrimônio", publicado no mesmo livro:

\author{
I) \\ a taturana cuida bem dos pelos \\ nenhum amassado \\ (MEDEIROS, 2012, p. 71).
}

O que percebemos nos versos de Medeiros é um rastro, um vestígio da ontologia presente no canto Bororo; uma concepção de mundo mais próxima do perspectivismo ameríndio do que da filosofia ocidental. Conforme explica o antropólogo Eduardo Viveiros de Castro, para a cosmologia ameríndia, a consciência, a cultura e a subjetividade não são exclusividade dos humanos; os animais possuem "uma intencionalidade ou subjetividade formalmente idêntica à consciência humana, materializável, digamos assim, em um esquema corporal humano oculto sob a máscara animal" (2002, p. 351). Isso significa que o corpo (natureza) é o que distingue os seres, enquanto a alma (cultura) aquilo que as une: "Uma só 'cultura', múltiplas 'naturezas", diz a famosa máxima de Viveiros de Castro sobre o multinaturalismo, ou seja, sobre a concepção ameríndia que supõe a cultura como universal e a natureza como forma do particular. Ao contrário do pensamento ocidental que supõe uma dualidade ontológica entre natureza e cultura; para o pensamento ameríndio, há uma continuidade entre estas duas esferas, justamente porque os seres naturais são dotados de disposições humanas e características sociais (VIVEIROS DE CASTRO, 2000, p. 428).

O que muda não é a maneira como os seres veem o mundo (todos pensam da mesma forma, todos são dotados de cultura), mas o mundo que veem. Dessa maneira, o sangue é cauim (cerveja de mandioca) para a onça, a lama é um salão cerimonial para as antas, os vermes sobre a carne podre são caça temperada com pimenta para os urubus, e por aí afora. Também por isso, os animais predadores veem os humanos como nós vemos aquilo que caçamos, enquanto nossa caça nos vê como animais predadores. Daí um yawalapíti concluir que, se as onças comem os humanos e os humanos comem os macacos, "gente é macaco de onça" (VIVEIROS DE CASTRO, 2002, p. 48) - é por isso que elas nos atacam e nos devoram, pois nos veem como caça.

\footnotetext{
Enquanto o corpo diferencia as espécies, a alma as assemelha como humanas. Nesse sentido, os Wari' são um caso exemplar do pensamento perspectivista ameríndio. Todos os humanos partilham práticas culturais análogas: vivem em família, caçam, cozinham seus alimentos, ingerem bebidas fermentadas, fazem festas etc. Os diferentes corpos, entretanto, implicam formas diferentes de perceber as mesmas coisas. Assim, tanto os Wari' como o jaguar bebem chicha de milho, mas o que o jaguar vê como chicha é o sangue, do mesmo
} 
modo que o barro é chicha para a anta. Tanto o jaguar como a anta se concebem como humanos, wari', termo que significa "gente", "nós", e percebem os Wari' como nãohumanos, podendo predá-los como se fossem caça, ferindo-os com suas flechas (VILAÇA, 2000).

Entre os inúmeros exemplos que poderíamos citar, cabe resgatar um mito Arekuna que é emblemático neste sentido, ele conta a história de um menino criado como filho por uma anta. Vejamos uma parte da narrativa anotada por Lévi-Strauss em $O$ cru e o cozido:

\begin{abstract}
a anta cobre o filho adotivo de carrapatos à guisa de miçangas: "Ela os colocou em volta do pescoço dele, nas pernas, nas orelhas, nos testículos, debaixo do braço, no corpo todo"; para ela, a cobra venenosa é uma chapa para assar os beijus de mandioca, o cão é uma cobra venenosa... (LÉVI-STRAUSS, 2010, p. 316).
\end{abstract}

O mesmo mito é pensado por Medeiros em Totens. No poema "O músico e os carrapatos", ele conta como Enrique Flor, que tocava em casamentos "atiçando e ativando o sex appeal dos vegetais", reconhece pérolas no colar de carrapatos do rapaz, como se também o músico fosse capaz de assumir a perspectiva da anta:

a anta grávida foi morta a flechadas na floresta não muito longe do acampamento

ao lado do corpo dela os caçadores viram um rapazinho atônito com vários colares de carrapatos vivos

ele havia desaparecido da aldeia que ficava longe dali meses atrás

Enrique Flor saltou da rede e foi para lá correndo apesar de grave infecção nos pés e percebeu assombrado que os carrapatos não eram carrapatos eram pérolas

o rapazinho mais tarde lhe confirmou que eram efetivamente pérolas

mas sua avó então lhe deu um banho demorado como se as pérolas fossem efetivamente só carrapatos

(MEDEIROS, 2012, p. 61).

O mito foi publicado pela primeira vez em 1916, no livro Mitos e lendas dos índios Taulipangue e Arekuná, pelo alemão Theodor Koch-Grünberg, e posteriormente resgatado na coleção de narrativas indígenas Makunaíma e Jurupari: cosmogonias ameríndias, de 2002, também organizada por Sérgio Medeiros, de onde retiro essa citação:

O rapaz encontrou uma cascavel (tsekaság) e gritou: "Cuidado! Uma cobra!” e correu. A anta correu atrás dele. Então pararam e disseram: "Vamos ver!" Voltaram para junto da cobra. Aí a anta disse: "Isto não é cobra! É o meu fogão!". Ela explicou: "Dizem que a 
cobra corre atrás para morder. Mas isto não é cobra. Para nós, antas, o cachorro é uma cobra!" Disse mais: "A cobra corre atrás da gente e onde ela morde, dói. A cobra para nós é um fogão. Os homens a consideram uma cobra e sofrem com a mordida, como nós sofremos com uma mordida de cão". E a anta seguiu avante com o rapaz, que agora sabia que a cobra era um fogão, e não se assustou mais (KOCH-GRÜNBERG apud MEDEIROS, 2002, p. 233).

Conforme explica o próprio Medeiros, no ponto de vista da anta existem dois mundos diferentes: um familiar e um não-familiar ao rapaz, "poético, onírico, abundante", onde os carrapatos são pérolas e a cobra um fogão (a imagem remete à cobra enrolada que se parece com a chapa redonda onde os índios assam os bolos de mandioca). Trata-se de um "mundo da metáfora, da imagem, do duplo sentido, da polissemia, enfim, da poesia", analisa Medeiros (2002, p. 233). Segundo ele, as lições de estética da anta transformam o feio em bonito e provocam uma espécie de reviravolta ou "estranhamento" na experiência do menino, que passa a viver "num mundo ambíguo, em que o sentido literal dos termos não é mais válido". Para a anta, que vive no mundo poético, a metáfora é o sentido literal; e é o menino quem está lendo o mundo com "os olhos errados", ela precisa, portanto, introduzi-lo "no universo do sentido figurado, revelando-lhe a ambigüidade das palavras, para ajudá-lo a sobreviver naquele universo onírico e opulento que defini como paragem mítica". Tais paragens míticas, onde se abandona o mundo familiar e as identidades se confundem, onde tudo tem duplo sentido, ocorrem, explica Medeiros, quando se entra na mata ou no rio (2002, p. 236).

Podemos pensar que, ao serem atravessados pela estética/ética ameríndia, poetas, tradutores, editores, cineastas entram nestas paragens míticas onde as identidades se confundem e a racionalidade ocidental é colocada em questão, de forma que o ritmo, a sintaxe, a linguagem da obra de arte é afetada e transformada, iluminando questões caras à teoria da arte na contemporaneidade.

No caso do cinema, isso fica bastante evidente no projeto Vídeo nas Aldeias, criado em 1986, pelo cineasta Vincent Carelli, que realiza oficinas de formação audiovisual em diferentes comunidades indígenas. Dos 70 filmes produzidos pela ONG, mais da metade são de autoria indígena (se é que é possível falar em autoria em filmes cuja principal característica é a coletividade). Conforme aponta Ivana Bentes, o projeto desperta um pensamento não apenas sobre o uso das imagens na antropologia, na etnografia ou nas ciências sociais, como também "dá visibilidade aos impasses em torno do documentário contemporâneo que vêm problematizando temas como a produção da auto-imagem, a fabulação, a construção do real, a nossa relação com a imagem do outro, temas recorrentes em toda uma série de filmes" (BENTES, 2015).

Vejamos, por exemplo, a questão da fabulação que, desde Jean Rouch e seu $E u$, um negro, de 1958, se tornou uma problemática importante no cinema documentário. Em Das crianças Ikpeng para o mundo, de 2001, realizado por Natuyu Txicão, Karané Txicão e Kumaré Txicão, sob a coordenação de Mari Corrêa e Vincent Carelli, quatro crianças Ikpeng apresentam suas famílias, seu cacique, seus costumes, suas brincadeiras. As crianças interpretam seus avós, enquanto aprendem tradições que haviam sido perdidas no contato com o branco, como a fabricação de flechas com penas, o uso de uma concha específica para raspar a mandioca, a preparação da comida antes das panelas de alumínio, a pesca com timbó, etc. Ensina Kamatxi, enquanto pesca com seus amigos: 
Vocês estão vendo? Era assim que nossos avós cortavam timbó. Não se machucavam, nem a cobra os picava. Vocês estão vendo a espuma? Ela se mistura na água quando batemos o timbó. Ela é muito amarga e por isso mata os peixes. Assim os meus avós amarravam o timbó. Eles batiam o timbó na lagoa para matar peixes para suas mulheres.

Esse aprendizado/brincadeira se torna uma ficção diante da câmera, uma performance. Há uma sequência emblemática neste sentido, quando as meninas brincam que são mulheres adultas com seus filhos na floresta; elas penduram a rede, guardam o beiju pra quando tiverem fome e saem catar yarú, então encontram uma onça e acabam caindo assustadas na fuga: "Estamos cansadas. Ficamos com medo da onça e caímos no caminho. Vamos descansar. Nunca mais vamos voltar lá. Só com os nossos maridos. Vamos dormir. Já estamos dormindo", diz Yuwipo como uma atriz que explica seu papel.

Esse tipo de encenação está presente em todo o filme, inclusive no ritual de passagem dos meninos com suas máscaras e das meninas com suas pinturas. Aliás, pode-se dizer que se trata de um filme sobre a performatividade, sobre aprender a ser índio, sobre inventar-se como povo. Conforme percebeu Amaranta Cesar em análise de outros dois filmes do projeto, Bicicletas de Nhanderú e Hipermulheres, "a encenação do ritual não é apenas um espetáculo para o outro, mas também, e talvez sobretudo, uma forma de performar-se como índio, e, como diz [Carlos] Fausto, de lutar 'contra a ameaça de que as gerações futuras não saibam mais 'virar índios para eles mesmos' (FAUSTO, 2010, p. 167)" (CESAR, 2012, p. 94).

A arte cinematográfica é utilizada pelos indígenas como instrumento de performatividade e fabulação, mas também de rememoração e reinvenção do cotidiano a partir do passado. De forma que o cinema assume aquela que, segundo Deleuze, seria a tarefa da arte, especialmente da arte cinematográfica: "não dirigir-se a um povo suposto, já presente, mas contribuir para a invenção de um povo" (DELEUZE, 1990, p. 259). Neste sentido, o documentário não é um cinema da verdade, mas a verdade do cinema (segundo a expressão de Jean Rouch), um acontecimento histórico, um gesto político de resistência, capaz de se esquivar da dominação cultural, de provocar um pensamento sobre nós enquanto outros e de expor nossos preconceitos.

Sobre isso, cabe lembrar uma cena bastante reveladora (e incômoda) de outro filme do projeto, Duas aldeias, uma caminhada, de 2008, desenvolvido pelo Coletivo Mbya-Guarani de Cinema: um dos diretores, Ariel Ortega, entrevista um turista branco em São Miguel Arcanjo (RS); sentado sob a perspectiva de uma câmera constrangedora, o turista diz, para o próprio índio com a câmera, que a situação dos índios é muito triste, porque são "sujos e dependentes de dinheiro". Cenas como essas nos deixam absolutamente desconfortáveis diante da evidência dos discursos etnocêntricos que, em outras situações (se não fossem os próprios indígenas os entrevistadores), talvez, passassem despercebidos.

Mas não é apenas o jogo de poder invertido entre entrevistador-índio e entrevistado-branco o que coloca nosso etnocentrismo em evidência. Também como espectadores somos desafiados por esses vídeos. Conforme explica Carelli, ao contrário do que o público parece esperar, os índios não se comportam como vítimas, para que o branco possa expressar sua compaixão e sua solidariedade, "muito pelo contrário, a 
alegria, a brincadeira, o humor, são marcas do convívio entre eles" (CARELLI, 2015); tampouco se apresentam como passivos diante do processo de dominação da cultura branca, pois têm plena consciência da mudança pela qual estão passando. "Há toda uma discussão e uma dinâmica interna em andamento entre as gerações, incorporando algumas coisas de fora, rejeitando outras, preservando a memória de tradições e abandonando outras" (CARELLI, 2015). Coloca-se em xeque, assim, todo um pensamento civilizatório e uma política indigenista oficial que busca distinguir os índios entre "autênticos" e "civilizados". Contra este ideal perverso de pureza, que tem efeitos, inclusive, "na demarcação dos territórios indígenas e na garantia de sobrevivência dos povos" (CARELLI, 2015), os cineastas indígenas utilizam a tecnologia branca para contar sua própria história, resgatar sua tradição, refletir sobre a captura de sua imagem, rememorar suas lutas e ganhar visibilidade.

Desde o advento do Cinema Verdade, uma das principais preocupações do cinema documentário tem sido a complexa relação de poder que se estabelece entre aquele que detém a câmera e aquele que tem sua imagem captada, o embate ético entre sujeito e objeto de conhecimento. Já em 1979, Jean Rouch vislumbrava um tempo "de uma câmera tão 'participante' que ela passará automaticamente para as mãos daqueles que até aqui estavam na frente dela. Assim, o antropólogo não terá mais o monopólio da observação, ele mesmo será observado, gravado, ele e sua cultura" (apud QUEIROZ, 2015). Esse tempo chegou, um tempo de deslocamento do sujeito da enunciação, quando o sujeito que emprega a palavra outro "aceita ser um 'outro' para o 'outro"' (BERNARDET, 2015). Uma descentralização capaz de, como afirma Rancière, "reconstruir o âmbito de nossas percepções e o dinamismo de nossos afetos" e, com isso, abrir "passagens possíveis para novas formas de subjetivação política" (RANCIÈRE, 2014, p. 81) que redefinem o que é visível, o que se pode dizer deste visível e que sujeitos são capazes de fazê-lo. Um gesto capaz de reconfigurar a experiência comum do sensível, de reembaralhar as fronteiras entre sujeito criador e objeto da arte ou do conhecimento, visíveis e invisíveis, dizíveis e indizíveis, mesmidade e alteridade, eu e outro.

A arte não como fixação do eu, mas como ficção do eu (ficcionalização do euartista ou do eu-espectador), fricção do eu com muitas outras coisas que o contagiam, afetação infinita e múltipla. Afinal, o ser, nos mostra Jean-Luc Nancy (2006), é sempre um ser-com, que circula no com e pelo com da co-existência singularmente plural. Daí que, para o autor de Ser Singular Plural, existir é sempre co-existir, ex-istir, existir para fora, para o outro. De forma que a essência da existência humana está no ex, como exílio do eu na exterioridade, na alteridade, na multiplicidade e na alteração (NANCY, 1996, p. 35).

Enquanto devir-minoritário e reconfiguração da partilha do sensível, a arte nos arranca do lugar confortável que o eu ocupava como indivíduo protegido pelas filosofias da consciência de si. Segundo Emmanuel Lévinas, é nessa "incessante implosão da identificação", na "ignição da pele tocando", no Mesmo que desperta de si, "desembriagando-se de sua identidade e de seu ser" (2008, p. 52) que está a vivacidade

\footnotetext{
2 “Eu, não intercambiável, sou eu apenas na medida em que sou responsável”, diz Lévinas (2007, p. 80).
} 
da vida; e, podemos dizer também, da arte. A arte como este espaço onde o eu desaparece para reaparecer como nós - Nancy diz que a verdade do ego sum é um nos sumus (2006, p. 49) -, para se ex-por como "devir entre multiplicidades", como ser aberto, como ser-com, no e pelo mundo.

\section{REFERÊNCIAS}

ANTELO, Raul. "La traducibilidad posfundacional (Sobre Meu destino é ser onça, de Alberto Mussa)". In: CÁMARA, Mario; DI LEONE, Luciana; TENNINA, Lucía (comps.). Experiencia, cuerpo y subjetividades: nuevas reflexiones. Literatura argentina y brasileña del presente. Buenos Aires: Santiago Arcos Editor, 2011.

ATTRIDGE, Derek. The Singularity of Literature. New York: Routledge, 2004.

BARTHES, Roland. O rumor da língua. Prefácio Leyla Perrone-Moisés. Trad. Mario Laranjeira. $2^{\mathrm{a}}$ ed. São Paulo: Martins Fontes, 2004.

BENTES, Ivana. "Câmera muy very good pra mim trabalhar". Vídeo nas Aldeias. Disponível em: http://www.videonasaldeias.org.br/2009/biblioteca.php?c=11. Acesso em: junho de 2015.

BERNARDET, Jean-Claude. "Vídeo nas aldeias, o documentário e a alteridade". Vídeo nas Aldeias. Disponível em: http://www.videonasaldeias.org.br/2009/biblioteca.php?c=22. Acesso em: junho de 2015. CARELLI, Vincent. "Moi, un Indien". Catálogo Mostra Vídeo nas Aldeias. Disponível em: http://issuu.com/videonasaldeias/docs/cat_logo_vna_2004_-_completo2. Acesso em: junho de 2015. CESAR, Amaranta. "Tradição (re)encenada: o documentário e o chamado da diferença". Revista Devires. Belo Horizonte, v.9, n.1, p 86-97. jan/jun 2012.

COHN, Sergio (org.). Poesia. br: cantos ameríndios. Rio de Janeiro: Beco do Azougue, 2012.

DELEUZE, Gilles. Crítica e clínica. Tradução de Peter Pál Pelbart. São Paulo: Editora 34, 1997. . A Imagem-Tempo. Tradução de Eloisa de Araújo Ribeiro. São Paulo: Brasiliense, 1990. ; GUATTARI, Félix. Mil Platôs - Capitalismo e Esquizofrenia. v. II. Tradução de Ana Lúcia de Oliveira e Lúcia Cláudia Leão. Rio de Janeiro: Ed. 34, 1995.

DERRIDA, Jacques. Anne Dufourmantelle convida Jacques Derrida a falar Da hospitalidade. Tradução de Antonio Romane. São Paulo: Escuta, 2003.

O animal que logo sou. Tradução de Fábio Landa. São Paulo: Editora UNESP, 2002.

FOUCAULT, Michel. A ordem do discurso. 13 ${ }^{\text {a }}$ ed. Trad. Laura Fraga de Almeida Sampaio. São Paulo: Edições Loyola, 2006.

HELDER, Herberto. Ouolof. Lisboa: Assírio \& Alvim, 1997.

LÉVI-STRAUSS, Claude. O pensamento selvagem. Tradução de Tânia Pellegrini. Campinas: Papirus, 1989.

$\overline{\text { Cosac Naify, } 2010 .}$

O cru e o cozido - Mitológicas. v. 1. Tradução de Beatriz Perrone-Moisés. $2^{\mathrm{a}}$ ed. São Paulo:

LÉVINAS, Emmanuel. De Deus que vem à idéia. Tradução de Pergentino Stefano Pivatto. Petrópolis:

Editora Vozes, 2008.

Ética e Infinito. Tradução de João Gama. Lisboa: Edições 70, 2007. 1993.

Humanismo do outro homem. Tradução de Pergentino S. Pivatto (org.). Petrópolis: Vozes,

LÖWY, Michael. Walter Benjamin: aviso de incêndio. Trad. Wanda Nogueira Caldeira Brant. Tradução das teses Jeanne Marie Gagnebin, Marcos Lutz Müller. São Paulo: Boitempo, 2005.

MEDEIROS, Sérgio. (org.) Makunaíma e Jurupari: cosmogonias ameríndias. São Paulo: Perspectiva, 2002.

Totens. São Paulo: Iluminuras, 2012.

MUSSA, Alberto. Meu destino é ser onça. $2^{\text {a }}$ ed. Rio de Janeiro: Record, 2009.

PELBART, Peter Pál. A vertigem por um fio. Políticas da subjetividade contemporânea. São Paulo: Editora Iluminuras, 2000. 
QUEIROZ, Ruben Caixeta de. "Política, estética e ética no projeto Vídeo nas Aldeias". Vídeo nas Aldeias. Disponível em: http://www.videonasaldeias.org.br/2009/biblioteca.php?c=20. Acesso em: junho de 2015.

RANCIÈRE, Jacques. O espectador emancipado. Tradução de Ivone Benedetti. São Paulo: Martins Fontes, 2014.

SANTIAGO, Silviano. Uma literatura nos trópicos: ensaios sobre dependência cultural. São Paulo: Perspectiva, 1978.

VILAÇA, Aparecida. "O que significa tornar-se outro? Xamanismo e contato interétnico na Amazônia". In: Revista Brasileira de Ciências Sociais, v. 15, n. 4, pp. 56-72. 2000.

VIVEIROS DE CASTRO, Eduardo. A inconstância da alma selvagem e outros ensaios de antropologia. São Paulo: Cosac \& Naify, 2002.

"Os pronomes cosmológicos e o perspectivismo ameríndio". In: ALLIEZ, Éric (org.). Gilles

Deleuze: Uma Vida Filosófica. São Paulo: Ed. 34, 2000.

Recebido em 05/10/2015. Aprovado em 23/10/2015.

Title: Amerindian perspectives in contemporary aesthetics

Abstract: The proposal of this work is to reflect on intercultural experiences that are open to Amerindian images, narratives, poetics, aesthetics and onthology: the Video nas Aldeias project, the restoration of the Tupinambá myth in Alberto Mussa's Meu destino é ser onça, Herberto Helder's translation to Caxinauá myth, and the decentralization of Brazilian literary canon in Poesia.br, organized by Sergio Cohn. Projects that borrow its techniques (literary, cinematographic, translational, editorial) so the other can speak for himself and for us as others. On this contact, Brazilian contemporary literature and cinema are affected by a becoming-minor that digs a minor language in the major language and destabilize the standard culture.

Keywords: Literature. Cinema. Amerindian onthology. 